\title{
Safety and Efficacy of Transcatheter Arterial Chemoemboliazation in the Real-Life Management of Unresectable Hepatocellular Carcinoma
}

\author{
Argyro Mazioti ${ }^{1}$, Nikolaos K. Gatselis ${ }^{2}$, Christos Rountas ${ }^{1}$, Kalliopi Zachou ${ }^{2}$, Dimitrios K. \\ Filippiadis ${ }^{1}$, Kostantinos Tepetes ${ }^{3}$, George K. Koukoulis ${ }^{4}$, Ioannis Fezoulidis ${ }^{1}$, George N. \\ Dalekos $^{2, *}$ \\ ${ }_{2}^{1}$ Department of Radiology, Medical School, University Hospital of Larissa, University of Thessaly, Larissa, Greece \\ 2 Department of Medicine and Research Laboratory of Internal Medicine, Medical School, University of Thessaly, Larissa, Greece \\ ${ }_{4}^{3}$ Department of Surgery, Medical School, University Hospital of Larissa, University of Thessaly, Larissa, Greece \\ 4 Department of Pathology, Medical School, University of Thessaly, Larissa, Greece \\ *Corresponding author: George N. Dalekos, Department of Medicine and Research Laboratory of Internal Medicine, School of Medicine, University of Thessaly, Biopolis, 41110 Larissa, \\ Greece. Tel: +30-2413502285, Fax: +30-2413501557, E-mail: dalekos@med.uth.gr.
}

Received: July 03, 2012; Revised: September 19, 2012; Accepted: November 18, 2012

\begin{abstract}
Background: Trans-arterial chemoembolization (TACE) is associated with better survival in BCLC-stage B patients with hepatocellular carcinoma (HCC) and Child-Pugh A whereas in Child-Pugh B there is no definite evidence of benefit.

Objectives: To assess the safety and efficacy of TACE during routine clinical practice in a consecutive Greek cohort of patients with unrespectable HCC.

Patients and Methods: Seventy one patients enrolled for this study (mean follow-up:24.6 months). $100 \mathrm{mg}$ cisplatin, 50 mg doxorubicin and $10 \mathrm{ml}$ lipiodol as well as embolic materials were used. CT-scans and blood tests were obtained prior and post-TACE. Kaplan-Meier method and Cox proportional hazard model were used to evaluate survival and factors affecting survival.

Results: Survival at 1-year, 2-years, 3-years and 5-years was 73.2\%, 45.4\%, 33.2\% and 14.9\% respectively. Procedure-related mortality was 1.4\%. Multivariate analysis showed lesion diameter, Child-Pugh classification, alcohol abuse, tumor response and AFP prior TACE as independent prognostic factors of survival. Patients diagnosed during surveillance had significantly better survival rates compared to those diagnosed after development of symptoms ( $\mathrm{HR}=0.58,95 \% \mathrm{CI}: 0.33-1.01, \mathrm{P}<0.05)$.

Conclusions: TACE is safe and efficient for unrespectable HCC. Alcohol abuse, tumor burden, response criteria, Child-Pugh and AFP prior to the session were identified as independent predictors of survival whereas, adherence to surveillance programs resulted in significantly better survival in these patients.
\end{abstract}

Keywords: Chemoembolization, Therapeutic; Carcinoma, Hepatocellular; Liver Cirrhosis; Hepatitis B Virus; Hepatitis C

\section{Background}

HCC is the third most common cause of tumor-related death among males and the sixth among females; without effective treatment the reported median survival is less than 5 months (1). In Greece, data from the HEPNET-GREECE Study Group has shown a cumulative HCC incidence approaching in 5 years $20 \%$ and $10 \%$ in decompensated and compensated HBV-related cirrhosis, respectively (2-4). In contrast, HCC incidence is less than $4 \%$ in HBV patients without cirrhosis whereas for HCV patients the incidence was even lower (1.4\%) (2-4). Surgical resection and liver transplantation are the most effective treatments for early or very early HCC according to the BCLC staging-system $(5,6)$. However, many patients are presented with unrespectable HCC in the so-called intermediate stage according to BCLC (BCLC-stage B) where TACE is recommended as the standard care by many authorities (5-10). TACE seems to work well in prolonging the 2-year survival (OR in 35\% of patients) particularly in BCLC-stage B patients with preserved liver function (Child-Pugh A) compared to the best supportive care or systemic chemotherapy $(8,11,12)$. In HCC cases with ChildPugh B, a case-by-case decision for TACE treatment seems mandatory, to be taken by multidisciplinary teams $(8,11$, 12). In this context, several uncertainties have been raised

Implication for health policy/practice/research/medical education:

Hepatocellular carcinoma (HCC) prognosis is not favorable due to the lack of reliable symptoms for the diagnosis of early or very early stage HCC, aggressive nature of the disease, concurrent liver decompensating and occasionally because of limited availability of potential treatment options although its management is very costly for any healthcare structure. Therefore, safe and cost-effective management of the HCC burden in real life practice is of great importance. Trans-arterial chemoembolization (TACE) seems safe and efficient for unrespectable HCC cases in routine clinical practice whereas independent predictors of favorable response should be taken into account by a multidisciplinary team in an individualized manner. Of note, adherence to surveillance programs for HCC diagnosis seems to carry significantly better survival in these patients.

Copyright (C) 2013, Kowsar Corp.; Licensee Kowsar Ltd. This is an Open Access article distributed under the terms of the Creative Commons Attribution License (http:|| creativecommons.org/licenses/by/3.0), which permits unrestricted use, distribution, and reproduction in any medium, provided the original work is properly cited. 
in every day clinical practice regarding factors affecting TACE modality like tumor burden, selection criteria, chemotherapeutic regimens and use or disuse of lipiodol, use and the type of embolizing agents and the frequency of TACE courses.

\section{Objectives}

Accordingly, the aim of the present study was to assess the safety and efficacy of TACE as well as the survival rates and the potential risk factors affecting survival during this routine clinicalpractice in a consecutive Greek cohort of patients with unrespectable HCC.

\section{Patients and Methods}

All participants included in this study were patients with unrespectable HCC who attended our clinic from 6/2003-9/2010 and consented to participate. Overall, 71 patients enrolled for TACE including 53/71 (74. 6\%) with BCLC-stage B and 12/71 (16.9\%) with BCLC-stage A in whom the risk of surgery or radiofrequency ablation was high. In addition, 2 had BCLC-stage $C$ and 4 BCLC-stage D for whom TACE was provided because their performance status was 1-2; sorafenib was not available during that time, liver disease was stable without ascites and they had a solitary tumor. The clinical, epidemiological and demographic data of patients are shown in Table 1. HCC diagnosis was made according to EASL and AASLD ( 7 , 9 ). Accordingly, 37 patients had typical CT findings, 30 had two coincident imaging techniques and 4 had CT and positive biopsy under CT-guidance. Most patients (43/71; 60.6\%) were asymptomatic and diagnosis was established during 6-monthly surveillances with AFP and ultrasound. In the remaining, HCC was diagnosed after admission for several reasons; e.g. highly elevated transaminases in a random check-up, abdominal pain, weight loss, etc.. Exclusion criteria included: extra hepatic metastases, active gastrointestinal bleeding, hepatic encephalopathy, refractory ascites or any known contraindication of TACE (i.e. impaired coagulation tests and renal failure). All subjects consented to participate by a written consent form. The ethical committee of the Medical School, University of Thessaly, Larissa, Greece approved the protocol.

Table 1. Clinical, Epidemiological and Demographic Characteristics as Well as Response Rates According to RECIST and EASL Criteria in 71 Patients With Hepatocellular Carcinoma Treated by Trans-arterial Chemoembolization

\begin{tabular}{|lc|}
\hline & No. (\%) \\
\hline Gender & \\
\hline Male & $61(85.9)$ \\
\hline Female & $10(14.1)$
\end{tabular}

Age, $y$, Mean \pm SD

Autoimmune Hepatitis

No 69 (97.2)

Yes

$2(2.8)$

Alcohol abuse

No

$41(57.7)$

Yes

$30(42.3)$

Chronic Hepatitis B

No

Yes $40(56.3)$

Chronic Hepatitis C

No $60(84.5)$

Yes $11(15.5)$

Primary Biliary Cirrhosis

No $69(97.2)$

Yes $2(2.8)$

HCC $^{\mathrm{a}}$

Solitary $37(52.1)$

Multinodular 34 (47.9)

Lesion diameter, $\mathrm{cm}$, Mean $\pm \mathrm{SD}$ $7.4 \pm 5.5$

Number of sessions, Mean \pm SD $2 \pm 2$

Child-Pugh classification

A $47(66.2)$ $20(28.7)$ $4(5.6)$

C

$\mathbf{C R}^{\mathrm{a}}$ $6(8.5)$

PD $^{\mathrm{a}}$ $20(28.2)$

$\mathbf{P R}^{\mathrm{a}}$ $39(54.9)$

$\mathrm{SD}^{\mathrm{a}}$ $23(32.4)$

Response rates $\left(\right.$ EASL $\left.^{\mathrm{a}}\right)$

CR

PD $6(8.5)$

PR $12(16.9)$

SD $30(42.3)$

Objective response (OR) according to RECIST

$\mathbf{O R}^{\mathrm{a}}$ $26(36.6)$

$\mathbf{N R}^{\mathrm{a}}$ $45(63.4)$

Objective response (OR) according to EASL

OR

${ }^{a}$ Abbreviations: CR, complete response; EASL, European association for the study of the liver; HCC, hepatocellular carcinoma; NR, nonresponders; $\mathrm{OR}$, Objective response; $\mathrm{PD}$, progressive disease; $\mathrm{PR}$, partial response; RECIST, response evaluation criteria in solid tumors; SD, stable disease 


\subsection{Imaging and Laboratory Studies}

Dynamic CT-scan of the liver was performed for all patients prior and one month post TACE. For the evaluation of tumor response, tumor diameters as well as the percentage of viable (enhancing) tumor were taken into account according to the RECIST and EASL criteria $(9,13)$. An area that retained lipiodol for over one month was considered necrotic. All CT-scan evaluations were done by two radiologists (AM and CR). Standard laboratory markers including complete blood counts, coagulation tests, creatinine, urea and liver function tests (AST, ALT, $\gamma$-GT, LDH, ALP, total and direct bilirubin) were determined 1-day prior and 2-days post TACE. AFP was determined according to our 6-monthly surveillance program but also 1-day prior and one month post TACE.

\subsection{TACE}

A mixture of 100mg cisplatin, 50mg doxorubicin and $10 \mathrm{ml}$ lipiodol together with $10-15 \mathrm{ml}$ of non-ionic, water-soluble contrast material was used for all patients. In cases of multinodular disease in one hepatic lobe, a lobar chemoembolization was performed at the level of right/left hepatic artery, whereas for single lesions a selective or superselective approach was done. Embolic agents (embospheres) were used only in cases of selective/superselective chemoembolization (18 patients) in order to minimize the potential damage of the nontumorous liver. TACE sessions were repeated until the tumor became completely necrotic. In fact, repetitions of TACE were performed in two-month intervals on the basis of tumor response on CT and patient tolerance that were assessed before any new course. Unsuccessful TACE treatment was considered when tumor growth or appearances of new tumors were observed after appropriate number of TACE sessions. The survival rate of patients was calculated from the date of first TACE (follow-up stopped 9/2010; mean follow-up 24.6 months). TACE-related death was considered as any death that occurred within 60 days of the session.

\subsection{Statistical Analysis}

Results are expressed as mean \pm SD or SE and medianIQR, where appropriate. Data were analyzed by Student's t-test, Mann-Whitney U, paired t-test, Wilcoxon sign rank test, ANOVA, multivariate survival analysis using Cox proportional-hazard models with 95\% CI and Kaplan-Meier survival analysis, where applicable. A twosided p value of less than 0.05 was considered statistically significant.

\section{Results}

Most patients (43/71; 60.5\%) were discharged 2-days af- ter TACE. In total, 153 TACE procedures were performed (average number/patient: 2.16 ). In the majority of patients $(34 / 71 ; 47.9 \%)$ one TACE session was done, in 18 (25.3\%) two, in $9(12.7 \%) 3$, in 4 (5.6\%) 4 and in the remaining 3 patients (4.2\%) 5, 6 and 11 sessions were done in each of them respectively. TACE-related mortality was 1 out of 71 (1.4\%). Post-embolization syndrome as attested by mild to moderate abdominal pain, low-grade fever and acute phase response (e.g. leukocytosis, elevation of transaminases and C-reactive protein) was observed in all patients, yet in all but one, the syndrome was lelflimited. Severe liver decompensation and abdominal pain was observed in only one patient with multinodular HCC and partial portal vein thrombosis. This patient was hospitalized for 13 days and died 1.5 months after the procedure. Tumor response rates according to RECIST and EASL are shown in Table 1. Patients were classified as having PR, SD, CR, PD or NR (defined as SD plus PD; Table 1). The OR rate was defined as CR plus PR (Table 1) whereas, disease control rate was defined as OR plus SD (91.6\% and 91.5\% according to EASL and RECIST, respectively). The changes in laboratory parameters before and after TACE and according to the treatment response (OR vs. NR) are shown in (Appendixes 1 , 2 and 3). Patients with OR demonstrated a significantly higher increase of bilirubin compared to that found in NR whereas, AFP decreased in OR but not in NR (Appendixes 1, 2 and 3).

\subsection{Survival}

By the last follow-up 76.1\% of patients had died. Mean survival was 2.5 years $(\mathrm{SE}=0.3$ ). The survival curve is shown in Figure 1. The use of embospheres did not affect the response rates and survival (data not shown). The main causes of death were: progressive liver failure (27 patients), variceal bleeding (5 patients), sepsis (4 patients) and non-liver-related reasons in the remaining patients. Univariate analysis revealed that multinodular HCC, lesion diameter, Child -Pugh classification, alcohol abuse, liver function tests, AFP prior TACE and RECIST and EASL classification were predictive prognostic factors of survival (data not shown). However, after multivariate survival analysis only the lesion diameter, Child-Pugh classification, alcoholrelated cirrhosis, tumor response according to EASL criteria and AFP prior the session were independent prognostic factors of survival (Table 2). Survival was not affected by the BCLC B or BCLC A stage of patients ( $\mathrm{HR}=1.30,95 \% \mathrm{CI}$ : 0.61-2.78, P = 0.498; Supplement 1). On the contrary, hazard was significantly reduced for patients diagnosed during the screening surveillance compared to those diagnosed after the development of symptoms ( $\mathrm{HR}=0.58,95 \% \mathrm{CI}$ : 0.33-1.01, P < 0.05; Supplement 2). 


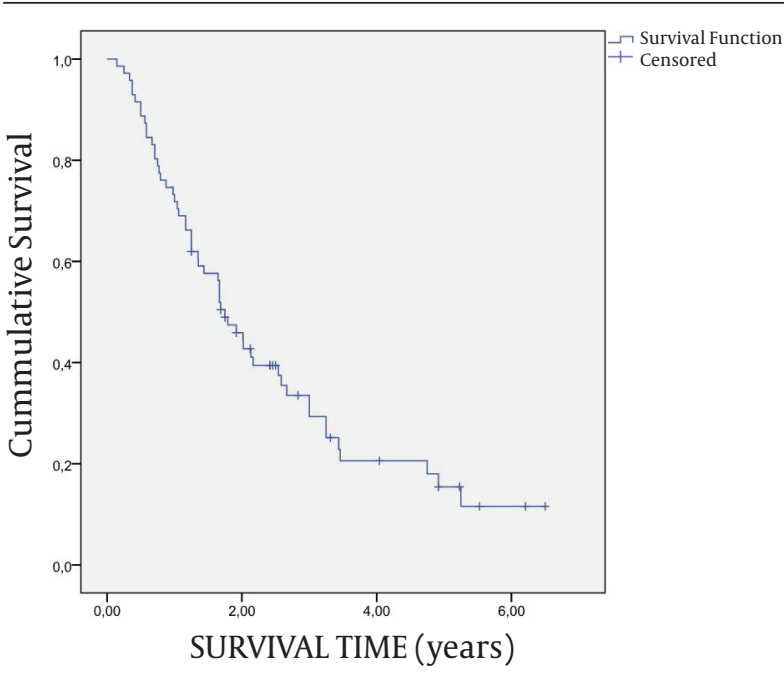

Figure 1. Survival rates of the patients according to Kaplan-Meier method. The cumulative survival rates at 6 months, 1-year, 2-years, 3-years and 5-years were 91.6\% ( $\mathrm{SE}=3.3 \%), 73.2 \%(\mathrm{SE}=5.3 \%), 45.4 \%(\mathrm{SE}=6.0 \%), 33.2 \%(\mathrm{SE}=$ $5.9 \%)$ and $14.9 \%(\mathrm{SE}=5.1 \%)$, respectively. $\mathrm{SE}=$ standard error

Table 2. Multivariate Analysis of Independent Prognostic Factors of Survival

\begin{tabular}{lll}
\hline & HR $\left.^{\mathrm{a}}(\mathbf{9 5} \% \mathrm{CI})^{\mathrm{a}}\right)$ & Pvalue \\
\hline $\begin{array}{l}\text { Lesion diameter, cm } \\
\text { Child-Pugh classification }\end{array}$ & $1.15(1.08-1.23)$ & $<0.001$ \\
\hline $\mathbf{A}$ & 1.00 & $<0.001$ \\
\hline B/C & $5.94(2.58-13.66)$ & \\
\hline Alcohol abuse & & 0.050 \\
\hline No & 1.00 & \\
Yes & $1.88(1-3.56)$ & \\
EASL & \\
OR $^{\mathrm{a}}$ & & \\
NR $^{\mathrm{a}}$ & 1.00 & \\
AFP $^{\mathrm{a}}$ prior TACE $^{\mathrm{a}}$ & $2.2(1.12-4.33)$ & \\
\hline
\end{tabular}

a Abbreviations: AFP, alpha fetoprotein; EASL, European association for the study of the liver; HR, hazard ratio; NR, non-responders; OR, Objective response; TACE, Trans-arterial chemoembolization; 95\%CI, confidence intervals

\section{Discussion}

The present study demonstrated that TACE was safe and well-tolerated in every-day clinical practice in a Greek cohort of patients with unresectable HCC. The mean cumulative 1-, 2-, 3- and 5-years survival rates were similar with two previous systematic reviews $(8,14)$. However, direct comparison of our results with previous reports $(8,14)$ cannot be done in a precise way since the results of these meta-analyses have been derived from studies that widely vary on the basis of patient selection criteria. Indeed, only selected patients are usually included in research trials, which is completely different from HCC patients encountered in routine clinical practice as studied in our report (12). Therefore, we tried to compare our results under real-life conditions with those revealed from studies using exactly or approximately the same procedures to our study. We found 6 studies in the English literature that completed the above mentioned criteria (15-20). In these studies including an overall 372 patients the reported 1-year, 2-years and 3-years survival rates were 50-75\%, $23.3-59 \%$ and $14.8-41 \%$, respectively which is in accordance with our findings. Regarding the hematological and biochemical markers, there was no significant change between prior and post TACE values when our patients were assessed according to the EASL criteria of response. This finding suggests that in patients with unresectable HCC who underwent TACE, the laboratory values prior and two days post the procedure cannot provide a preliminary hint concerning the likelihood of response to treatment. After multivariate analysis of alcohol abuse, lesion diameter, Child-Pugh classification, AFP level prior to the session and EASL classification were identified as independent prognostic factors of survival. Previous articles have already reported on the role of Child-Pugh classification, tumor size, AFP prior TACE and the proportion of tumor necrosis in the prediction of treatment response and survival $(13,21,22)$. To the best of our knowledge, alcohol abuse has not been identified as an independent predictor of treatment response and survival in patients with unrespectable HCC. Therefore, further studies seem necessary in order to define if in fact alcohol abuse is a negative prognostic factor affecting treatment response and ultimately survival. Last but not least, we showed that the adherence to surveillance program for HCC diagnosis affected positively the survival of the patients. In conclusion, we showed that TACE is a safe and efficient technique for the management of patients with unrespectable HCC under real-life conditions. Alcohol abuse, tumor burden, response rate criteria, Child-Pugh classification and AFP prior to the session were identified as independent predictors of survival. Adherence to surveillance programs for HCC diagnosis seems to carry significantly better survival in patients diagnosed during the screening surveillance than those diagnosed after the development of symptoms.

Appendix 1. Laboratory Findings Prior and Post TACE

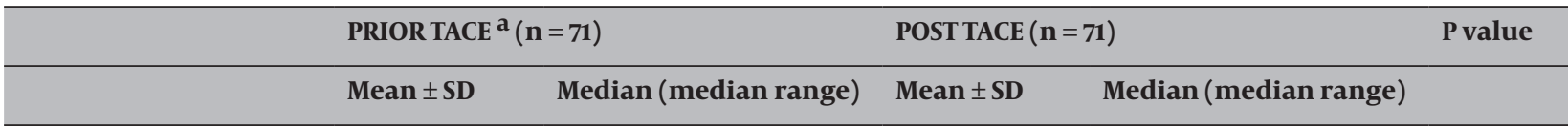


Mazioti A et al.

\begin{tabular}{|c|c|c|c|c|c|}
\hline $\mathbf{I N R}^{\mathrm{a}}$ & $1.2 \pm 0.3$ & $1.2(1-1.4)$ & $1.3 \pm 0.3$ & $1.3(1.1-1.5)$ & $<0.001$ \\
\hline Urea, mg/dL & $38.5 \pm 13.7$ & $36(28-47)$ & $41 \pm 12$ & $43(32-51)$ & 0.363 \\
\hline Creatinine, mg/dL & $0.9 \pm 0.2$ & $0.9(0.8-1)$ & $0.9 \pm 0.2$ & $0.9(0.8-1)$ & 0.923 \\
\hline Total protein ,g/dL & $7.5 \pm 0.7$ & $7.5(7-7.9)$ & $6.9 \pm 0.7$ & $6.9(6.4-7.6)$ & $<0.001$ \\
\hline Albumin, $\mathrm{g} / \mathrm{dL}$ & $3.7 \pm 0.6$ & $3.8(3.3-4.2)$ & $3.4 \pm 0.5$ & $3.4(3.1-3.8)$ & $<0.001$ \\
\hline Total bilirubin, mg/dL & $1.6 \pm 1.6$ & $1.1(0.7-2.1)$ & $2.4 \pm 2$ & $1.7(1.2-2.8)$ & $<0.001^{b}$ \\
\hline Direct bilirubin, mg/dL & $0.4 \pm 0.5$ & $0.3(0.2-0.5)$ & $0.6 \pm 0.6$ & $0.4(0.3-0.9)$ & $<0.001^{b}$ \\
\hline $\mathbf{A S T}^{\mathrm{a}}, \mathbf{U} / \mathbf{L}$ & $59.5 \pm 38.1$ & $45.5(32.5-84.5)$ & $137 \pm 105$ & $105(77-164)$ & $<0.001^{b}$ \\
\hline $\mathbf{A L T}^{\mathrm{a}}, \mathbf{U} / \mathbf{L}$ & $45.7 \pm 33.3$ & $33(22-57)$ & $96 \pm 109$ & $62(44-98)$ & $<0.001^{b}$ \\
\hline$\gamma-\mathbf{G T}{ }^{\mathrm{a}}, \mathbf{U} / \mathbf{L}$ & $120.3 \pm 121.4$ & $78.5(35-158.5)$ & $130 \pm 165$ & $82(35-169)$ & $0.013^{b}$ \\
\hline $\mathbf{A L P}^{\mathrm{a}}, \mathbf{U} / \mathbf{L}$ & $117.6 \pm 49.7$ & $114(84-137)$ & $115 \pm 95$ & $98(75-122)$ & $<0.001^{b}$ \\
\hline $\mathbf{L D H}^{\mathrm{a}}, \mathbf{U} / \mathbf{L}$ & $214.8 \pm 120.9$ & $192(164-228)$ & $279 \pm 103$ & $256(207-321)$ & $<0.001^{b}$ \\
\hline $\operatorname{AFP}^{\mathrm{a}}, \mathbf{n g} / \mathbf{m L}$ & $1206.6 \pm 3890.8$ & $41.6(4.5-195.9)$ & $680.5 \pm 2992.4$ & $27.6(4.5-94.0)$ & $0.399^{b}$ \\
\hline $\mathrm{WBC}^{\mathrm{a}}, \mathrm{x} \mathrm{10}^{3} / \mathrm{mm}^{3}$ & $6.2 \pm 3.2$ & $5.6(4.3-7.3)$ & $7.6 \pm 3.2$ & $7.1(5.3-9.2)$ & $<0.001$ \\
\hline HCT $^{\mathrm{a}}, \%$ & $38 \pm 6.4$ & $39(34.4-42.6)$ & $36.3 \pm 5.2$ & $37.2(31-40)$ & $<0.001$ \\
\hline PLT $^{\mathrm{a}}, \mathbf{x 1 0}^{3} / \mathrm{mm}^{3}$ & $156.6 \pm 79.5$ & $141(95.5-185)$ & $132 \pm 65$ & $120(80-160)$ & $<0.001$ \\
\hline
\end{tabular}

a Abbreviations: AFP, alpha-fetoprotein; ALT, alanine-aminotransferase; AST, aspartate-transaminase; $\gamma$-GT, gamma-glutamyl transferase; HCT, hematocrit; INR, international normaized ratio; LDH, lactate dehydrogenase; PLT, platelets; TACE, trans-arterial chemoembolization; WBC, white blood cells

b Statistical tests performed are paired t-test and Mann-Whitney U test

\begin{tabular}{|c|c|c|c|c|c|c|c|c|}
\hline & & PRIOR TACI & & POST TACE & & CHANGE & Pvalue $^{\mathrm{C}}$ & Pvalue $^{f}$ \\
\hline & $\begin{array}{l}\mathrm{OR}^{\mathrm{a}}(\mathbf{n}=35) \\
\mathbf{N R}^{\mathrm{a}}(\mathbf{n}=36)\end{array}$ & Mean \pm SD & $\begin{array}{l}\text { Median } \\
\text { (median range) }\end{array}$ & Mean $\pm S D$ & $\begin{array}{l}\text { Median } \\
\text { (median range) }\end{array}$ & Mean $\pm S D$ & & \\
\hline \multirow[t]{3}{*}{ INR a } & NR & $1.2 \pm 0.3$ & $1.2(1-1.3)$ & $1.3 \pm 0.3$ & $1.2(1.1-1.3)$ & $0.1 \pm 0.2$ & 0.062 & 0.091 \\
\hline & OR & $1.2 \pm 0.2$ & $1.1(1.1-1.4)$ & $1.4 \pm 0.3$ & $1.3(1.2-1.5)$ & $0.2 \pm 0.2$ & $<0.001$ & \\
\hline & Pvalue & 0.878 & & 0.348 & & & & \\
\hline \multirow{3}{*}{$\begin{array}{l}\text { Urea, } \\
\text { mg/dL }\end{array}$} & NR & $35.2 \pm 11.3$ & $33(27-41)$ & $44.1 \pm 10.7$ & $47(35-50)$ & $8.9 \pm 12.2$ & 0.006 & 0.011 \\
\hline & OR & $41.4 \pm 15$ & $41.5(30-52)$ & $38.5 \pm 11.9$ & $36(29-51)$ & $-2.9 \pm 15.7$ & 0.327 & \\
\hline & Pvalue $^{\mathrm{b}}$ & 0.066 & & 0.076 & & & & \\
\hline \multirow{3}{*}{$\begin{array}{l}\text { Creatinine, } \\
\text { mg/dL }\end{array}$} & NR & $0.9 \pm 0.2$ & $0.9(0.8-1)$ & $0.9 \pm 0.2$ & $0.9(0.8-1)$ & $0 \pm 0.2$ & 0.626 & 0.550 \\
\hline & OR & $1 \pm 0.2$ & $1(0.9-1)$ & $0.9 \pm 0.2$ & $0.9(0.8-1)$ & $-0.1 \pm 0.2$ & 0.685 & \\
\hline & Pvalue ${ }^{b}$ & 0.062 & & 0.529 & & & & \\
\hline \multirow{3}{*}{$\begin{array}{l}\text { Total protein, } \\
\text { g/dL }\end{array}$} & NR & $7.4 \pm 0.6$ & $7.4(7-7.8)$ & $6.8 \pm 0.8$ & $6.9(6.3-7.4)$ & $-0.6 \pm 0.7$ & 0.001 & 0.921 \\
\hline & OR & $7.6 \pm 0.8$ & $7.6(7.1-7.9)$ & $7 \pm 0.7$ & $6.9(6.4-7.6)$ & $-0.6 \pm 0.7$ & $<0.001$ & \\
\hline & Pvalue ${ }^{b}$ & 0.241 & & 0.350 & & & & \\
\hline \multirow{3}{*}{$\begin{array}{l}\text { Albumin, } \\
\text { g/dL }\end{array}$} & NR & $3.6 \pm 0.6$ & $3.7(3.3-4)$ & $3.4 \pm 0.5$ & $3.3(3.1-3.9)$ & $-0.2 \pm 0.3$ & $<0.001$ & 0.411 \\
\hline & OR & $3.8 \pm 0.6$ & $3.9(3.3-4.3)$ & $3.4 \pm 0.6$ & $3.4(3.1-3.8)$ & $-0.4 \pm 0.4$ & $<0.001$ & \\
\hline & P value b & 0.331 & & 0.813 & & & & \\
\hline \multirow{3}{*}{$\begin{array}{l}\text { Total biliru- } \\
\text { bin, mg/dL }\end{array}$} & NR & $1.8 \pm 1.7$ & $1.2(0.9-2.5)$ & $2.5 \pm 2.5$ & $1.9(1.1-2.7)$ & $0.7 \pm 1$ & $0.001 \mathrm{e}$ & $0.044^{\mathrm{f}}$ \\
\hline & OR & $1.5 \pm 1.5$ & $1.1(0.7-1.8)$ & $2.3 \pm 1.5$ & $1.7(1.2-2.9)$ & $0.8 \pm 1$ & $<0.001 \mathrm{e}$ & \\
\hline & P value ${ }^{b}$ & $0.196^{\mathrm{d}}$ & & 0.641 & & & & \\
\hline
\end{tabular}


Mazioti A et al.

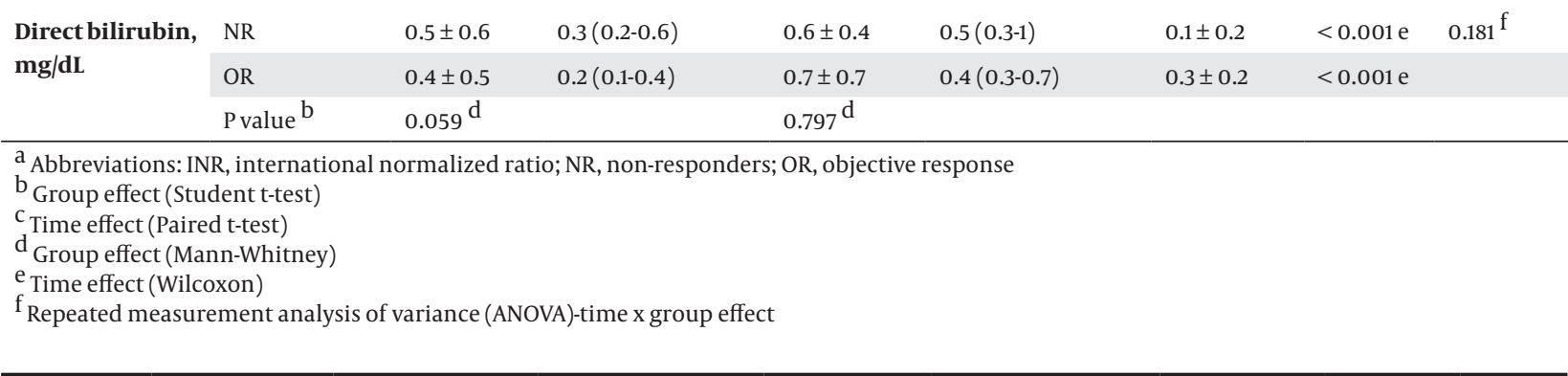

Appendix 3. Laboratory Findings Prior And Post TACE Classified According to EASL Criteria (Continued)

\begin{tabular}{|c|c|c|c|c|c|c|c|c|}
\hline & $\mathrm{OR}^{\mathrm{a}}(\mathbf{n}=35)$ & PRIOR TACE $^{\mathrm{a}}$ & & POST TACE & & CHANGE & Pvalue $^{c}$ & $\mathbf{P} \ddagger$ \\
\hline & & Mean \pm SD & $\begin{array}{l}\text { Median } \\
\text { (median range) }\end{array}$ & Mean \pm SD & $\begin{array}{l}\text { Median } \\
\text { (median range) }\end{array}$ & Mean \pm SD & & \\
\hline \multirow{3}{*}{$\begin{array}{l}\text { AST }^{a}, \\
\mathbf{U} / \mathbf{L}\end{array}$} & NR & $64.9 \pm 42.3$ & $55.5(37-87)$ & $127.3 \pm 89.1$ & $90(77-118)$ & $62.4 \pm 82.2$ & $<0.001^{\mathrm{e}}$ & $0.146^{\mathrm{f}}$ \\
\hline & OR & $54.7 \pm 34$ & $38.5(32-76)$ & $145 \pm 119.1$ & $108(75.5-172)$ & $90.3 \pm 115.5$ & $<0.001^{\mathrm{e}}$ & \\
\hline & Pvalue ${ }^{b}$ & 0.288 & & $0.568 \mathrm{~d}$ & & & & \\
\hline \multirow{3}{*}{$\begin{array}{l}\mathbf{A L T}^{\mathrm{a}}, \\
\mathbf{U} / \mathbf{L}\end{array}$} & NR & $42.1 \pm 26.4$ & $31.5(25-54)$ & $71.5 \pm 59$ & $57(44-72)$ & $29.4 \pm 49.3$ & $0.002^{e}$ & \multirow[t]{3}{*}{$0.298^{f}$} \\
\hline & OR & $48.8 \pm 38.5$ & $34(19-58)$ & $118.6 \pm 136.9$ & $87.5(47-141)$ & $69.8 \pm 134.7$ & $<0.0011^{\mathrm{e}}$ & \\
\hline & Pvalue ${ }^{b}$ & $0.111^{\mathrm{d}}$ & & $0.783 \mathrm{~d}$ & & & & \\
\hline \multirow{3}{*}{$\begin{array}{l}\gamma-\mathbf{G T}{ }^{a}, \\
\mathbf{U} / \mathbf{L}\end{array}$} & NR & $146.5 \pm 145$ & $91(43-227)$ & $156.3 \pm 137.9$ & $99(56.5-224)$ & $9.8 \pm 27.8$ & $0.107^{\mathrm{e}}$ & $0.501^{\mathrm{f}}$ \\
\hline & OR & $97.2 \pm 92$ & $61(32-137)$ & $106.9 \pm 185.1$ & $44(32.5-103)$ & $9.7 \pm 111.2$ & $0.055^{\mathrm{e}}$ & \\
\hline & Pvalue ${ }^{b}$ & $0.142^{d}$ & & $0.043 \mathrm{~d}$ & & & & \\
\hline \multirow{3}{*}{$\begin{array}{l}\mathbf{A L P}{ }^{a}, \\
\mathbf{U} / \mathbf{L}\end{array}$} & NR & $131.3 \pm 52$ & $124(92-143)$ & $114.8 \pm 47$ & $114(83-124)$ & $-16.5 \pm 16.1$ & $<0.0011^{\mathrm{e}}$ & $0.128^{f}$ \\
\hline & OR & $105.4 \pm 44.9$ & $99(72-130)$ & $115.4 \pm 123$ & $89.5(59-122)$ & $10 \pm 100.3$ & $0.011^{\mathrm{e}}$ & \\
\hline & Pvalue ${ }^{b}$ & 0.039 & & $0.155 \mathrm{~d}$ & & & & \\
\hline \multirow[t]{3}{*}{$\begin{array}{l}\text { LDH }{ }^{a}, \\
\text { U/L }\end{array}$} & NR & $200.7 \pm 38.5$ & $197(173-228)$ & $\begin{array}{l}285.7 \pm \\
107.9\end{array}$ & $269(196.5-322)$ & $85 \pm 103.3$ & $0.003^{e}$ & $0.202^{f}$ \\
\hline & OR & $226.7 \pm 160.6$ & $181.5(160.5-216.5)$ & $273.2 \pm 101.6$ & $243(209-321)$ & $46.5 \pm 110.7$ & $0.001^{\mathrm{e}}$ & \\
\hline & Pvalue b & $0.338^{d}$ & & 0.695 & & & & \\
\hline \multirow[t]{3}{*}{$\begin{array}{l}\text { AFP }{ }^{a}, \\
\text { ng/mL }\end{array}$} & NR & $2319.8 \pm 5459.6$ & $85.7(4-457.4)$ & $\begin{array}{l}1368.4 \pm \\
4792.8\end{array}$ & $28.9(6.2-379)$ & $\begin{array}{ll}-951.4 & \pm \\
2539.4 & \end{array}$ & $0.184^{e}$ & $0.341^{f}$ \\
\hline & OR & $224.4 \pm 765.1$ & $38.1(5.3-142.8)$ & $284.4 \pm 952.6$ & $27.6(4.2-65)$ & $1461 \pm 5222$ & $0.042^{\mathrm{e}}$ & \\
\hline & Pvalue ${ }^{b}$ & 0.246 & & $0.840 \mathrm{~d}$ & & & & \\
\hline \multirow{3}{*}{$\begin{array}{l}\mathrm{WBC}^{\mathrm{a}}, \\
\mathrm{x10}^{3} / \mathrm{mm}^{3}\end{array}$} & NR & $6.3 \pm 3.2$ & $5.7(3.7-7.5)$ & $8.1 \pm 2.9$ & $7.6(6.3-9.4)$ & $1.8 \pm 2.4$ & 0.001 & 0.091 \\
\hline & OR & $6.2 \pm 3.2$ & $5.2(4.4-7.3)$ & $7 \pm 3.4$ & $6.7(4.7-7.7)$ & $0.8 \pm 2.1$ & 0.112 & \\
\hline & Pvalue ${ }^{b}$ & 0.868 & & 0.258 & & & & \\
\hline \multirow{3}{*}{$\begin{array}{l}\mathbf{H C T}^{\mathrm{a}}, \\
\%\end{array}$} & NR & $37.1 \pm 7.4$ & $38.7(33-42.4)$ & $36.3 \pm 4.9$ & $38.1(32-40)$ & $-0.8 \pm 2.9$ & 0.017 & 0.307 \\
\hline & OR & $38.9 \pm 5.2$ & $39(36-42.8)$ & $36.3 \pm 5.6$ & $36.3(30.4-41)$ & $-2.6 \pm 2.8$ & $<0.001$ & \\
\hline & Pvalue ${ }^{b}$ & 0.268 & & 0.957 & & & & \\
\hline \multirow{3}{*}{$\begin{array}{l}\text { PLT }^{\mathrm{a}}, \\
\mathbf{x 1 0 ^ { 3 }} / \mathbf{m m}^{3}\end{array}$} & NR & $158 \pm 74.7$ & $147(105-175)$ & $136.1 \pm 61.1$ & $121.5(89-158)$ & $-21.9 \pm 39.8$ & 0.037 & 0.207 \\
\hline & OR & $155.4 \pm 84.9$ & $121(94-185)$ & $127.7 \pm 69$ & $115.5(73-162)$ & $-27.7 \pm 59$ & 0.005 & \\
\hline & P value ${ }^{b}$ & 0.898 & & 0.650 & & & & \\
\hline
\end{tabular}

\footnotetext{
a Abbreviations: AFP, alpha-fetoprotein; ALT, alanine-aminotransferase; AST, aspartate-transaminase; $\gamma$-GT, gamma-glutamyl transferase; HCT, hematocrit; LDH, lactate dehydrogenase; PLT, platelets; TACE, trans-arterial chemoembolization; WBC, white blood cells

${ }^{\mathrm{b}}$ Group effect(Student t-test)

${ }^{\mathrm{c}}$ Time effect (Paired t-test)

d Group effect (Mann-Whitney)

e Time effect (Wilcoxon)

$\mathrm{f}_{\text {Time effect (Repeated measurement analysis of variance (ANOVA)-time } \mathrm{x} \text { group effect) }}$
} 


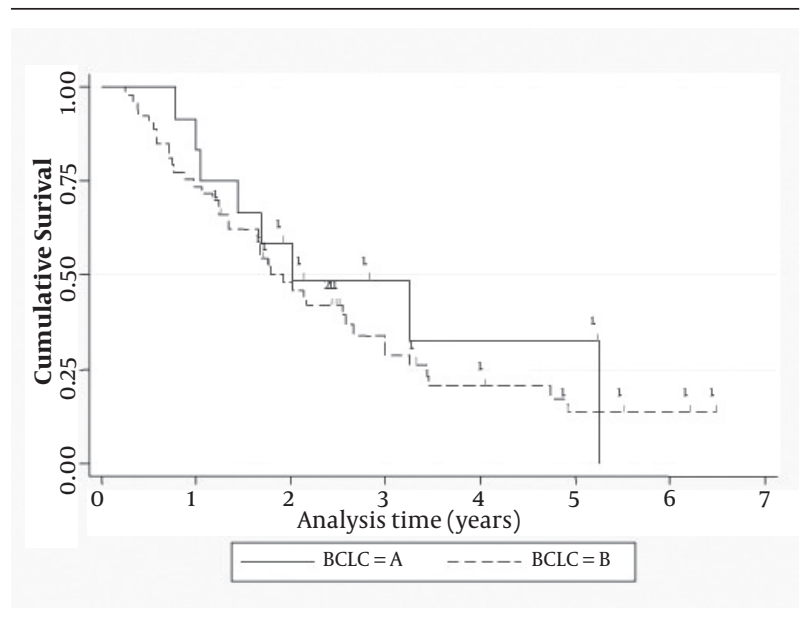

Supplement 1. Kaplan-Meier Survival Estimates According to BCLC Stage

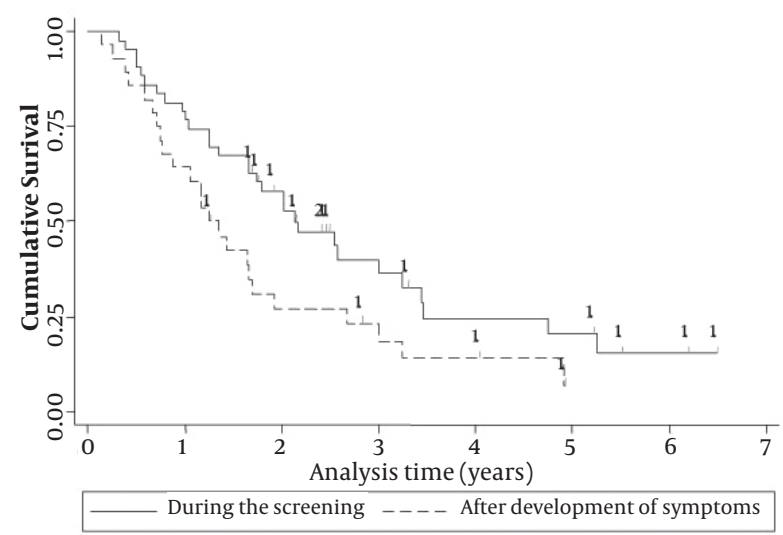

Supplement 2. Kaplan-Meier Survival Estimates for Patients Diagnosed During the Screening Surveillance Program and Patients Diagnosed After the Development of Symptoms

\section{Acknowledgements}

We are indebted to all our patients included in the study.

\section{Authors' Contribution}

$\mathrm{AM}, \mathrm{KZ}$, IF and GND had the original idea for the study, designed the study protocol and wrote the paper. NK, KZ, KT and GND recruited the patients, did the follow-up and the clinical diagnosis of the patients and along with AM, CR, DKF, GKK and IF assessed the patients from the clinical, virological, histological and radiological points of view. GKK did the interpretation of the histological data of the patients. AM, CR, DKF and IF performed the interventional treatment (TACE). AM, KZ, NG, KT and GND followed the patients post-treatment and in collaboration with CR, DKF and IF collected the whole data, and performed the follow-up assessment while contributed to the final version of the paper. GKK, NG, AM, KZ and GND wrote the final version of the paper. All authors have seen and approved the final draft of the paper.

\section{Financial Disclosure}

The authors have nothing to declare.

\section{Funding/Support}

The authors have nothing to declare.

\section{References}

1. Nordenstedt $\mathrm{H}$, White DL, El-Serag HB. The changing pattern of epidemiology in hepatocellular carcinoma. Dig Liver Dis. 2010;42 Suppl 3:S206-14.

2. Manesis EK, Papatheodoridis GV, Touloumi G, Karafoulidou A, Ketikoglou J, Kitis GE, et al. Natural course of treated and untreated chronic HCV infection: results of the nationwide Hepnet.Greece cohort study. Aliment Pharmacol Ther. 2009;29(10):1121-30.

3. Papatheodoridis GV, Lampertico P, Manolakopoulos S, Lok A. Incidence of hepatocellular carcinoma in chronic hepatitis B patients receiving nucleos(t)ide therapy: a systematic review. $J$ Hepatol. 2010;53(2):348-56.

4. Papatheodoridis GV, Manolakopoulos S, Touloumi G, Vourli G Raptopoulou-Gigi M, Vafiadis-Zoumbouli I, et al. Virological suppression does not prevent the development of hepatocellular carcinoma in HBeAg-negative chronic hepatitis B patients with cirrhosis receiving oral antiviral(s) starting with lamivudine monotherapy: results of the nationwide HEPNET. Greece cohort study. Gut. 2011;60(8):1109-16.

5. Llovet JM, Burroughs A, Bruix J. Hepatocellular carcinoma. Lancet. 2003;362(9399):1907-17.

6. Raoul JL, Sangro B, Forner A, Mazzaferro V, Piscaglia F, Bolondi L, et al. Evolving strategies for the management of intermediatestage hepatocellular carcinoma: available evidence and expert opinion on the use of transarterial chemoembolization. Cancer Treat Rev. 2011;37(3):212-20.

7. Bruix J, Sherman M. Management of hepatocellular carcinoma: an update. Hepatology. 2011;53(3):1020-2.

8. Llovet JM, Bruix J. Systematic review of randomized trials for unresectable hepatocellular carcinoma: Chemoembolization improves survival. Hepatology. 2003;37(2):429-42.

9. Llovet JM, Di Bisceglie AM, Bruix J, Kramer BS, Lencioni R, Zhu AX, et al. Design and endpoints of clinical trials in hepatocellular carcinoma.J Natl Cancer Inst. 2008;100(10):698-711.

10. Sangro B, D'Avola D, Inarrairaegui M, Prieto J. Transarterial therapies for hepatocellular carcinoma. Expert Opin Pharmacother. 2011;12(7):1057-73.

11. Llovet JM, Bruix J. Novel advancements in the management of hepatocellular carcinoma in 2008. J Hepatol. 2008;48 Suppl 1:S20-37.

12. Piscaglia F, Bolondi L. The intermediate hepatocellular carcinoma stage: Should treatment be expanded? Dig Liver Dis. 2010;42 Suppl 3:S258-63.

13. Therasse P, Arbuck SG, Eisenhauer EA, Wanders J, Kaplan RS, Rubinstein L, et al. New guidelines to evaluate the response to treatment in solid tumors. European Organization for Research and Treatment of Cancer, National Cancer Institute of the United States, National Cancer Institute of Canada. J Natl Cancer Inst. 2000;92(3):205-16.

14. Marelli L, Stigliano R, Triantos C, Senzolo M, Cholongitas E, Davies N, et al. Transarterial therapy for hepatocellular carcinoma: which technique is more effective? A systematic review of cohort and randomized studies. Cardiovasc Intervent Radiol. 2007;30(1):6-25.

15. Jaeger HJ, Mehring UM, Castaneda F, Hasse F, Blumhardt G, Loehlein D, et al. Sequential transarterial chemoembolization for unresectable advanced hepatocellular carcinoma. Cardiovasc 
Intervent Radiol.1996;19(6):388-96.

16. Kirchhoff TD, Bleck JS, Dettmer A, Chavan A, Rosenthal H, Merkesdal S, et al. Transarterial chemoembolization using degradable starch microspheres and iodized oil in the treatment of advanced hepatocellular carcinoma: evaluation of tumor response, toxicity, and survival. Hepatobiliary Pancreat Dis Int 2007;6(3):259-66.

17. Mabed M, Esmaeel M, El-Khodary T, Awad M, Amer T. A randomized controlled trial of transcatheter arterial chemoembolization with lipiodol, doxorubicin and cisplatin versus intravenous doxorubicin for patients with unresectable hepatocellular carcinoma. Eur J Cancer Care (Engl). 2009;18(5):492-9.

18. Shah SR, Riordan SM, Karani J, Williams R. Tumour ablation and hepatic decompensation rates in multi-agent chemoembolization of hepatocellular carcinoma. QJM.1998;91(12):821-8

19. Terzi E, Golfieri R, Piscaglia F, Galassi M, Dazzi A, Leoni S, et al. Re- sponse rate and clinical outcome of HCC after first and repeated cTACE performed "on demand". J Hepatol. 2012;57(6):1258-67.

20. Vogl TJ, Trapp M, Schroeder H, Mack M, Schuster A, Schmitt J, et al. Transarterial chemoembolization for hepatocellular carcinoma: volumetric and morphologic CT criteria for assessment of prognosis and therapeutic success-results from a liver transplantation center. Radiology. 2000;214(2):349-57.

21. Miraglia R, Pietrosi G, Maruzzelli L, Petridis I, Caruso S, Marrone $G$, et al. Predictive factors of tumor response to trans-catheter treatment in cirrhotic patients with hepatocellular carcinoma: a multivariate analysis of pre-treatment findings. World J Gastroenterol. 2007;13(45):6022-6.

22. Zhang JW, Feng XY, Liu HQ, Yao ZW, Yang YM, Liu B, et al. CT volume measurement for prognostic evaluation of unresectable hepatocellular carcinoma after TACE. World J Gastroenterol. 2010;16(16):2038-45. 